\title{
NILAI-NILAI PENDIDIKAN KARAKTER DALAM TIGA CERITA RAKYAT KULISUSU DI KABUPATEN BUTON UTARA
}

\author{
Oni Sutriasni ${ }^{1}$, Sahlan ${ }^{2}$, Erny Harijaty ${ }^{3}$ \\ pbsi.fkip.uho@gmail.com \\ 1,2,3, Jurusan Pendidikan Bahasa dan Sastra Indonesia, \\ Fakultas Keguruan dan Ilmu Pendidikan, Universitas Halu Oleo \\ Kampus Hijau Bumi Tridharma Anduonohu, Kendari, Indonesia
}

\begin{abstract}
ABSTRAK
Penelitian ini bertujuan untuk mendeskripsikan nilai-nilai pendidikan karakter yang terkandung dalam cerita rakyat Kulisusu. Jenis penelitian merupakan penelitian lapangan dan metode yang digunakan dalam penelitian ini adalah metode deskriptif kualitatif. Data dalam penelitian ini adalah data lisan yang berasal dari tuturan lisan informan yang dipakai dan diungkapkan dalam cerita rakyat Kulisusu di Kabupaten Buton Utara.Teknik pengumpulan data dalama penelitian ini menggunakan teknik wawancara, rekam, dan catat. Teknik anaslis data dalam penelitian ini menggunakan pendekatan sosiologi sastra. Sesuai dengan hasil penelitian ini bahwa nilai-nilai pendidikan karakter dalam tiga cerita rakyat Kulisusu di Kabupaten Buton Utara (1) Zaenab te Hamid, antara lain: (a) nilai pendidikan karakter religius, (b) nilai pendidikan karakter kerja keras, (c) nilai pendidikan karakter mandiri, (d) nilai pendidikan karakter rasa ingin tahu, (e) nilai pendidikan karakter gemar membaca, dan (f) nilai pendidikan karakter peduli social (2) Randasitagi te Puteri Waeri,antara lain: (a) nilai pendidikan karakter kerja keras, (b) nilai pendidikan karakter mandiri, (c) nilai pendidikan karakter rasa ingin tahu, (d) nilai pendidikan karakter peduli sosial, dan (e) nilai pendidikan karakter tanggung jawab. dan (3) Raja Indara Pitara, antara lain: (a) nilai pendidikan karakter kerja keras, (b) nilai pendidikan karakter rasa ingin tahu, (c) nilai pendidikan karakter bersahabat/komunikatif, (d) nilai pendidikan karakter peduli sosial, dan (e) nilai pendidikan karakter tanggung jawab.
\end{abstract}

Kata Kunci: nilai; pendidikan, karakter; cerita rakyat; sosiologi sastra 


\begin{abstract}
This study aims to describe the values of character education contained in the Kulisusu folklore. This type of research is field research and the method used in this research is descriptive qualitative method. The data in this study are oral data derived from the informants' oral speech which is used and expressed in the Kulisusu folklore in North Buton Regency. The data collection techniques in this study use interview, record, and note-taking techniques. The data analysis technique in this study uses a sociological literature approach. In accordance with the results of this study that the values of character education in the three Kulisusu folk tales in North Buton Regency (1) Zaenab te Hamid, include: (a) the value of religious character education, (b) the value of hard work character education, (c) the value of independent character education, (d) the value of curiosity character education, (e) the value of character education for fond of reading, and $(f)$ the value of character education for social care (2) Randasitagi te Puteri Waeri, among others: (a) the value of character education hard work, $(b)$ the value of independent character education, (c) the value of curiosity character education, $(d)$ the value of character education for social care, and (e) the value of character education for responsibility. and (3) Raja Indara Pitara, among others: (a) the value of hard work character education, (b) the value of curiosity character education, $(c)$ the value of friendly / communicative character education, (d) the value of character education for social care, and (e) the value of responsible character education.
\end{abstract}

Keywords: value; character building; folklore; sociology of literature 


\section{PENDAHULUAN}

Tumbuhnya kesusastraan Indonesia berawal dari bermulanya kesusastraan daerah.Sehingga antara sastra daerah dengan kesusastraan Indonesia tidak dapat dipisahkan. Pembinaan dan pengembangan sastra daerah merupakan usaha ke arah pengembangan sastra Indonesia pada umumnya.Hal ini dimaksudkan, karena sastra daerah merupakan tulang punggung dan khasanah pengungkap dan pelengkap kebudayaan nasional atau kesusastraan nasioanl.

Cerita rakyat merupakan hasil karya sastra lama yang dituturkan secara lisan dari mulut ke mulut oleh masyarakat pendukungnya. Di dalamnya sarat dengan muatan nilai yang sangat berharga bagi kehidupan yang mencerminkan budaya luhur daerah sekaligus sebagai cermin budaya yang diharapkan dapat berperan dalam upaya memperkaya khazana kehidupan nasional (Rahmawati, 2010: 139)

Seperti halnya daerah-daerah lain, di kalangan masyarakat Kulisusu juga banyak ditemui jenis cerita rakyat. Di antara cerita rakyat tersebut adalah "Latondotondoteu, La Ohe-oheo, Hamid te Zaenab, Randasitagi te Puteri Waeri Wondu, Raja Indara Pitara, Wa Ode Bilahi, Tegensano, Waupu Yi Loji, La Nggori-Nggori dan nggulisusu, Konde Rumamba dan Wita Linandu, Sangiano Doule, Tandai Bhale, Raha Bulelenga, Langkei-kei, Langkimbokimbohu, Wacimoku, Ndokua dan lain-lain". Dari beberapa cerita tersebut peneliti telah memilih tiga cerita rakyat, yaitu cerita rakyat Hamid te Zaenab, Randasitagi te Puteri Waeri Wondu, dan Raja Indara Pitara.

Upaya pelestarian sastra lisan tiga ceirita rakyat "Hamid dan Zaenab, Randasitagi dan Puteri Waeri Wondu, Raja Indara Pitara." dapat dimulai dengan penerjemahanan karya sastra dari bahasa Kulisusu ke bahasa Indonesia agar bisa dipahami oleh orang lain yang tidak mengerti bahasa Kulisusu. Peneliti memilih judul tersebut karena didasari atas hasil pembacaan dan pemahaman yang dilakukan oleh peneliti, dimana di dalam cerita rakyat tersebut mengandung nilai karakter sebagai pembentukkan kepribadian dan dapat dijadikan sebagai landasan dalam menjalankan kehidupan.
Nilai pendidikan karakter dalam karya sastra adalah pintu gerbang yang bisa membuat pembaca mengurungkan niat untuk melakukan kegiatan lain demi terus membaca halaman demi halaman dalam cerita. Deskripsi nilai pendidikan karakter yang mengisi cerita rakyat Kulisusu ternyata cukup memikat, misalnya:

Inade minai dhunia Hamid ilausako lumako masigi. Ilarono masigi, inade ingaji to'u tompari kando rongeo miahako.

Ketika ia turun ke bumi ia langsung menuju masjid. Di dalam masjid, ia terus mengaji hingga kedengaran oleh masyarakat

Pada kutipan diatas mencerminkan sosok Hamid yang menunjukkan perilaku positif dalam melaksanakan ajaran agama yang dianutnya. Membaca al-quran merupaka salah satu perintah sebagai umat islam. Kita sebagai umat islam kalau menjalankan perintah-Nya tentu akan mendapatkan ganjaran atau pahala. Manusia sebagai makhluk ciptaan Tuhantidak akan hidup kekal dan pasti akan kembali kepada sang penciptanya. Pada kutipan di atas dapat mengajarkan kita agar selalu menyepatkan waktu untuk menjalankan perintah-Nya, seperti belajar dan membaca ayat-ayat suci al-quran yang dapat membawa kebajikan bagi kita. Membaca al-quran juga dapat mendekatkan diri kepada sang pencipta dan memiliki beberapa manfaat dalam kehidupan seperti perilaku semakin baik karena terhindar dari perbuatan buruk.

Berdasarkan latar belakang di atas, maka rumusan masalah dalam penelitian ini yaitu nilai-nilai pendidikan karakter apa sajakah yang tekandung dalam tiga cerita rakyat Kulisusu di Kabupaten Buton Utara?

Penelitian ini bertujuan untuk mendeskripsikan nilai-nilai pendidikan karakter yang tekandung dalam tiga cerita rakyat Kulisusu di Kabupaten Buton Utara.

Dari hasil penellitian ini kelak diharapkan dapat bermanfaat sebagai berikut :

a. Sebagai upaya untuk mempertahankan sastra daerah khususnya cerita rakyat, serta pelestarian pencegahan dari ancaman kepunahan sastra daerah lisan dalam

3 | Jurnal BASTRA (Bahasa dan Sastra), Vol. 5 No.1, Edisi Januari 2020/e-ISSN: 2503-3875/ http://ojs.uho.ac.id/index.php/BASTRA 
rangka memperkaya kebudaan nasional di tengah-tengah perkembangan zaman

b. Bagi peserta didik diharpkan dapat menambah wawasan dalam mengapresiasi cerita rakyat, memahami dan mengamalkan nilai-nilai pendidikan karakter yang terkanduung didalamnya.

c. Sebagai bahan acuan dalam bahan pembelajaran khususnya bahasa dan sastra Indonesia yang bertujuan menanamkan nilai-nilai pendidikan karakter.

d. Dapat digunakan sebagai bahan studi perbandingan dalam upaya penelitian selanjutnya yang dianggap relevan, terutama penelitian ini terkait dengan Nilai-nilai Pendidikan dalam cerita rakyat.

\section{METODE PENELITIAN}

Metode dan Jenis Penelitian

Jenis Penelitian

Jenis penelitian ini dapat digolongkan ke dalam penelitian lapangan. Dikatakan demikian karena pengambilan data tiga cerita rakyat Kulisusu, peneliti secara langsung turun ke lapangan untuk mendapatkan data.

\section{Metode Penelitian}

Metode yang digunakan dalam penelitian ini adalah metode deskriptif kualitatif. Penggunaan metode ini bertujuan untuk mendeskripsikan secara sistematis, faktual, dan akurat dengan menggunakan katakata atau kalimat dan diuraikan sesuai dengan kenyataan yang ditemukan di lapangan penelitian.

Data dan Sumber Data

Data

Data yang digunakan dalam penelitian ini adalah data lisan, data lisan yang dimaksud adalah lisan berupa tiga cerita rakyat Kulisusu.

Sumber Data

Sumber data dalam penelitian ini adalah data lisan dari informan. Informan yang dimaksud adalah masyarakat Kulisusu yang mengetahui dan memahami cerita rakyat Kulisusudan merupakan penduduk asli serta penutur asli masyarakat Kulisusu di Kabupaten Buton Utara.

Teknik Pengumpulan Data

Teknik pengumpulan data yang digunakan dalam penelitian ini adalah sebagai berikut:

a. Teknik wawancara

b. Teknik rekaman

c. Teknik catat

Keabsahan Data

Pemeriksaan keabsahan data dianggap penting sehinggah hasil penelitian dapat dipertanggung jawabkan untuk memperoleh data yang sah (valid/kredibel).

Teknik Analisis Data

Dalam menganalisis data penelitian ini menggunakan pendekatan sosiologi sastra. Pendekatan sosiologi sastra merupakan ilmu yang mempelajari struktur sosial dan prosesproses sosial, Soekanto (Wicaksono, 2014: 38). Sosiologi merupakan ilmu yang mengkaji segala aspek kehidupan manusia yang meliputi masalah perekonomian, keagamaan, kebudayaan, aspek lainnya, dan mempelajari tumbuh dan berkembangnya manusia .Langkah kerja dengan menggunakan pendekatan sosioogi sastra ini yaitu mencari kesamaan dalam hal bahwa semuanya berurusan dengan hubungan sastra dengan masyarakat. Selanjutnya analisis data diuraikan sebagai berikut:

a. Mengidentifikasi data, artinya membaca, mendengarkan rekaman dan memahami seluruh cerita rakyat yang sudah dipilih dan diberi kode pada data yang sesuai dengan permasalahan penelitian.

b. Penerjemahan data yaitu berupa data cerita rakyat Kulisusuyang telah ditulis dan disusun dalam bahasa daerah selanjutnya diterjemahkan ke dalam bahasa Indonesia. Terjemahan dilakukan secara harfiah atau bebas dengan menyesuaikan arti dan pemahaman yang sesuai dengan kaidah bahasa Indonesia.

c. Analisis data, yaitu menganalisis data dengan metode yang sudah di tentukan, yakni metode deskriptif.

d. Deskripsi data, yaitu mendeskripsi nilainilai pendidikan karakter dalam cerita rakyat Kulisusu sesuai dengan

4 | Jurnal BASTRA (Bahasa dan Sastra), Vol. 5 No.1, Edisi Januari 2020/e-ISSN: 2503-3875/ http://ojs.uho.ac.id/index.php/BASTRA 
kemampuan peneliti agar hasil analisis itu mudah dipahami.

\section{HASIL PENELITIAN DAN PEMBAHASAN \\ 2.1 Deskripsi Nilai Pendidikan \\ Karakter dalam Cerita Rakyat Zaenab Tehamid}

\subsubsection{Nilai Pendidikan Karakter}

Religius

Religius merupakan sikap dan perilaku yang patuh dalam melaksanakan ajaran agama yang dianutnya, toleran terhadap pelaksanaan ibadah agama lain, dan hidup rukun dengan pemeluk Agama lain.Dalam cerita rakyat Zaenab te Hamid terdapat sikap yang mencerminkan nilai pendidikan karakter religius, seperti yang dilakukan oleh orang tua Zaenab dan Hamid yang ingin menanamkan sifat keagamaan terhadap diri anak-anaknya. Seperti pada kutipan berikut:

Inade minai dhunia Hamid ilausako lumako masigi. Ilarono masigi, inade ingaji to'u tompari kando rongeo miahako.

Ketika ia turun ke bumi ia langsung menuju masjid. Di dalam masjid, ia terus mengaji hingga kedengaran oleh masyarakat

Pada kutipan diatas mencerminkan sosok Hamid yang menunjukkan perilaku positif dalam melaksanakan ajaran agama yang dianutnya. Membaca al-quran merupaka salah satu perintah sebagai umat islam. Kita sebagai umat islam kalau menjalankan perintah-Nya tentu akan mendapatkan ganjaran atau pahala. Manusia sebagai makhluk ciptaan Tuhantidak akan hidup kekal dan pasti akan kembali kepada sang penciptanya. Pada kutipan di atas dapat mengajarkan kita agar selalu menyepatkan waktu untuk menjalankan perintah-Nya, seperti belajar dan membaca ayat-ayat suci al-quran yang dapat membawa kebajikan bagi kita. Membaca al-quran juga dapat mendekatkan diri kepada sang pencipta dan memiliki beberapa manfaat dalam kehidupan seperti perilaku semakin baik karena terhindar dari perbuatan buruk.

\subsubsection{Nilai pendidikan Karakter Kerja Keras}

Kerja keras merupakan perilaku yang menunjukkan upaya yang sungguh-sungguh dalam mengatasi berbagai hambatan belajar dan tugas, serta menyelesaikan tugas sebaikbaiknya. Kerja keras juga dapat diartikan bekerja mempunyai sifat yang bersungguhsungguh untuk mencapai sasaran yang ingin dicapai. Hal ini terdapat dalam cerita rakyat Zaenab te Hamid yang terlihat pada kutipan berikut:

Hamid ibalimo minai ana hinai to'ori ngumaji membali mia bumiasa to'u ngumaji.Inadepo ipoiami ipoiahandi budhiadhari tompari sawula.

Hamid mengubah dari seorang anak yang semula tidak tahu mengaji menjadi orang yang sangat pintar mengaji.

Dari kutipan cerita di atas menggambarkan upaya yang dilakukan oleh Hamid ketika berada di rumah si kakek.Dari anak yang semula tidak tahu menjadi sangat pintar. Hal ini mencerminkan karakter kerja keras Hamid untuk mencapai sesuatu ia perlu bersungguh-sungguh untuk mecapai hasil yang maksimal.

\subsubsection{Nilai Pendidikan Karakter \\ Mandiri}

Nilai pendidikan karakter mandiri merupakan sikap dan perilaku yang tidak mudah tergantung pada orang lain dalam menyelesaikan tugas-tugas. Dapat dilihat dalam kutipan berikut:

Inade kumora gumora akono ako hinai da'a lawanino minai tamano tompari kai momale.Inade tepotoromo kai pangka kai to'orio larono kuaikow inade ndo basiakomo mina rahando.

Dicarinya bapaknya, tetapi tidak ditemukannya.Iapun memanggilnya dan terus memanggil namun tetap tidak ada sahutan dari bapaknya. Hingga ia kecapean, ia tertunduk sambil menangis dan menyadari bahwa dirinya telah dibuang dari keluarga.

Dari kutipan cerita di atas menggambarkan sosok anak yang harus hidup tanpa keluarga. Karena dibuang oleh orang tua kandungnya sendiri, Hamid tak bisa berbuat apa-apa. Hamid pun tak seperti anak-anak lainnya yang menjalani hidup bersama keluarga mereka. Nilai pendidikan karakter mandiri berikutnya

5 | Jurnal BASTRA (Bahasa dan Sastra), Vol. 5 No.1, Edisi Januari 2020/e-ISSN: 2503-3875/ http://ojs.uho.ac.id/index.php/BASTRA 
msih terdapat pada cerita rakyat Zaenab te Hamid, yang melakukan sesuatu atas dorongan dan kebutuhannya sendiri.

\subsubsection{Nilai Pendidikan Karakter \\ Rasa Ingin Tahu}

Rasa ingin tahu merupakan sikap dan tindakan yang selalu berupaya untuk mengetahui lebih mendalam dan meluas dari sesuatu yang dipelajarinya, dilihat, dan didengar. Hal ini pula terdapat pada cerita rakyat "Zaenab te Hamid", Zaenab yang merasa penasaran dengan kehadiran seorang laki-laki tersebut yang sangat mirip dengan adiknya, berikut kutipannya:

Zaenab hinamo moiko pikirino tei kora mecukana laro wutono hapai anantama iso kai moiko te duka molino suarano kainadee mobaca ayat-ayat Qura'ani. Inade mooliako mamonaho inontono poate anantama iso yo Hamid.

Zaenab mulai tidak tenang dan sering bertanya-tanya dalam hati perihal pemudayang begitu syahdu membaca ayat-ayat suci al-quran.Ia pun ingin membuktikan kecurigaannya bahwa pemuda itu adalah adiknya, Hamid.

Kutipan di atas dikategorikan sebagai nilai pendidikan karakter rasa ingin tahu karena seorang kakak yang penasaran dan curiga terhadap apa yang telah ia lihat kepada laki-laki yang sedang membacakan ayat-ayat suci al-quran. Ia ingin membuktikan tentang apa yang dilihatnya. Zaenab menyelidiki dan mencari tahu dengan cara memperhatikan jari-jari Hamid untuk memastikan apakah cincin pemberiannya dikenakan oleh laki-laki itu. Namun, Hamid rupanya mengetahui maksud kakanya sehinggah ia selalu menyembunyikan tangannya agar Zaenab tidak melihatnya.Memasuki malam ketujuh barulah Hamid sengaja memperlihatkan jarinya yang mengenakan cincin pemberian kakaknya. Untuk mengetahui sesuatu kita perlu melakukan tindakan dan selalu berupaya untuk mengetahui lebih mendalam dan meluas dari suatu yang kita pelajari.

\subsubsection{Nilai Pendidikan Karakter Gemar Membaca}

Nilai pendidikan karakter gemar membaca adalah kebiasaan menyediakan waktu untuk membaca berbagai bacaan yang memberikan kebajikan bagi dirinya.Seperti dalam cerita rakyat Zaenab dan Hamidkegemaran membaca tersebut dicerminkan ketika Zaenab yang telah fasih membaca al-quran sedangkan Hamid belim bisa sama sekali. Berikut kutipan ceritanya:

Saarino inade pina'i dhunia, Hamid ilausako lumako masigi. Ilarono masigi, inade ingaji to'u tompari kando rongeo miahako

Ketika ia turun ke bumi, ia langsung menuju ke mesjid. Ia terus mengaji hinggah kedengaran oleh masyarakat.

Dari kutipan cerita di atas menggambarkan sikap Hamid yang selalu belajar untuk membaca. Pada waktu ia turun ke bumi, ia terus mengaji. Hamid yang menyediakan waktu untuk terus membaca al-quran dan memberikan kebajikan bagi dirinya.

\subsubsection{Nilai Pendidikan Karakter Peduli Sosial \\ Nilai pendidikan karakter peduli} sosial merupakan sikap dan tindakan yang selalu ingin memberi bantuan pada orang lain dan masyarakat yang membutuhkan. Berikut kutipan cerita:

Apuantama iko arino iboboihomo bendo lako sade poiaha. Tekamakidano apuantama iko, Hamid inao ilarono kadukaduno bajuno. Hamid isasio wumungkahio matano tabeano itenomo bo wumungkahio matano. Tempo iande itenao bo wumungkahio matano, Hamid inademo ilarono sade poiaha mokesato'u, larono poiaha iko kuaiko inade wawono kundo, ilipuno budhiadhari.

Kakek itu pun kemudian mengajaknya ke suatu tempat.Dengan kesaktian yang dimiliki oleh kakek itu, Hamid disimpannya ke dalam saku baju miliknya.Hamid dilarang membuka kedua kedua matanya kecuali setelah ada perintah untuk membuka mata. Setelah ia disuruh untuk membuka mata, Hamid telah berada di dalam sebuah istana yang sangat megah. Istana itu rupanya berada di atas awan, yakni di negeri kayangan.

Dari kutipan cerita di atas juga digambarkan rasa peduli seorang kakek kepada anak yang telah di buag oleh orang tuanya.Dengan rasa simpati si kakek tersebut

6 | Jurnal BASTRA (Bahasa dan Sastra), Vol. 5 No.1, Edisi Januari 2020/e-ISSN: 2503-3875/ http://ojs.uho.ac.id/index.php/BASTRA 
mengajak Hamid ke rumahnya karena Hamid tidak lagi memiliki tempat tinggal dan tujuan.Si kakek yang tidak mengetahui latar belakang Hamid tidak mempersoalkan hal itu untuk membantu Hamid.

Dalam hal ini, sebagai manusia yang berkarakter untuk membantu seseorang tidak perlu memilih-milih apakah mereka baik atau jahat.Sebab kepedulian mendorong kita untuk berperilaku apabila sesuatu terjadi maka kita rela memberikan tenaga, agar yang baik dan positiflah yang terjadi pada orang yang kita pedulikan.

\subsection{Deskripsi Nilai Pendidikan \\ Karakter dalam Cerita Rakyat \\ Randasitagi te Puteri Waeri Wondu}

\subsubsection{Nilai Pendidikan Karakter}

\section{Kerja Keras}

Kerja keras merupakan salah satu cara yang digunakan untuk mencapai ssuatu hal yang bersifat positif. Hal ini pula terdapat dalam cerita rakyat Randasitagi te Waeri Wondu yang terlihat pada kutipan berikut:

Bendo lako ikampo bolakoando aiko bea pesala itahi, sabucuno ndo lakomo itahi sando leuho tahi ndo poalamo bangka bosawikando. Wangkinamboro itotoro irope nai posala bei tondu, bangka iko kanamo aiko duka kai totoro iwana.

Untuk sampai ke kampung yang dituju, mereka harus menyebrangi laut. Ketika tiba dipinggir laut, mereka lalu mengambil sampan untuk tumpangan. Wa Ngkinamboro duduk di depan, tetapi sampan seakan-akan hampir tenggellam dibagian belakang, begitu pun ketika ia pindah untuk duduk dibagian belakang, sampan seakan-akan hampir tenggelam bagian belakang.

Kutipan cerita di atas menggambarkan nilai pendidikan karakter kerja keras yang digambarkan oleh usaha Wa Ngkinamboro untuk mencapai kampung halaman.Walaupun beberapa kali hampir tenggelam ia selalu berupaya agar sampan milik mereka tidak tenggelam. Ke uletan yang dilakukan Wa Ngkinamboro dalam mengatasi sampan yang hampir tenggelam tidak sia-sia, mereka sampai ke kampung halaman dengan selamat.

2.2.2 Nilai Pendidikan Karakter Mandiri
Nilai pendidikan karakter mandiri merupakan sikap dan perilaku yang tidak mudah tergantung pada orang lain dalam menyelesaikan tugas-tugas. Berikut kutipan cerita:

Sai to'ori mekabua ilakomo mekabua sai ponsakulako yo bua igaumo "mau naku poawa ika somano kaku poawa matano cinangku’.

Setelah La Ana-ana sudah tahu memancing, dia pun ke laut untuk memancing. Saat dia buang mata pancingnya, dia selalu menyertainya dengan perkataan (biar saya tidak dapat ikan yang penting saya dapat mata ibuku).

Dari kutipan di atas digambarkan bahwa seseorang yang selalu melakukan sesuatu atas dorongan sendiri untuk mencapai tujuan yang diinginkan karena kemandirian seseorang dapat bertindak bebas dengan norma-norma yang ditentukan.

\subsubsection{Nilai Pendidikan Karakter}

\section{Rasa Ingin Tahu}

Rasa ingin tahu yaitu sikap dan tindakan yang selalu berupaya untuk mengetahui lebih mendalam dan meluas dari sesuatu yang dipelajarinya, dilihat, dan didengar. Berikut kutipan cerita:

Sa'arino ilakomo iraha iko bei to 'orio kao inai moyiano te La Ana-ana dedepo katehingkano ipo 'onto cina dumano yi laro raha iko kuaiko yo Waeri Wondu, miarahano.

Dia pun pergi ke rumah tersebut untuk memastikan siapa yang tinggal bersama La Ana-ana dan betapa kagetnya dia melihat perempuan yang ada di dalam rumah tersebut ternyata adalah Waeri Wondu, istrinya.

Berdasarkan kutipan cerita di atas dapat dilihat bagaimana sikap rasa ingin tahu Randasitagi kepada La Ana-ana. Dengan rasa penasarannya, ia pun mengikuti La Ana-ana sampai ke rumahnya untuk memastikan dengan siapa La Ana-ana tinggal di rumah itu. untuk mengetahui sesuatu kita perlu mencari tahu atau menggali lebih dalam tentang apa yang ingin kita peroleh.

\subsubsection{Nilai Pendidikan Karakter}

Peduli Sosial

7 | Jurnal BASTRA (Bahasa dan Sastra), Vol. 5 No.1, Edisi Januari 2020/e-ISSN: 2503-3875/ http://ojs.uho.ac.id/index.php/BASTRA 
Nilai pendidikan karakter peduli sosial merupakan sikap dan tindakan yang selalu ingin memberi bantuan pada orang lain dan masyarakat yang membutuhkan. Seperti dalam cerita rakyat Randasitagi te Waeri Wondu, kepedulian Wa Tari Angka terhadap Waeri Wondu yang tengah hamil. Wa Tari Angka yang senantiasa membantu dan menjaga sambil menuggu kelahiran sang buah hati Waeri Wondu.

Sai ari aiko, Waeri Wondu ibansulemo irahando mpendua ipoia te Wa Tari Angka yo miamo jumagaio te mohalu akonomo yo tinorakono te sumikori anano bei lahiri. Nai lembahi dumamo anano ako dalumahiri iperonga te manu tama ana pina dumaano Waeri Wondu yo tama ndo ngehakonomo La Ana-ana.

Selain itu, Waeri Wondu kembali ke rumahnya dan tinggal bersama Wa Tari Angka sebagai orang yang selalu menjaganya dan mencarikan kebutuhan hidupnya sambil menunggu kelahiran anaknya.Tidak lama kemudian anaknya sudah lahir.Namun, saat kelahirannya dia kembar dengan seekor ayam jantan. Anaknya diberi nama La Ana-ana.

Dari kutipan cerita di atas juga mencerminkan kepedulian Wa Tari Angka terhadap Waeri Wondu yang sementara hamil. Sambil menunggu kelahiran sang anak Wa TariAngka senantiasa menyalurkan tenaganya untuk membantu Waeri Wondu dalam kehidupan sehari-hari. Karena orang yang peduli tidak akan menyakiti perasaan orang lain. Mereka selalu berusaha untuk menghargai, berbuat baik, dan membuat yang lain senang.

\subsubsection{Nilai Pendidikan Karakter \\ Tanggung Jawab}

Tanggung jawab merupakan sikap dan perilaku seseorang untuk melaksanakan tugas dan kewajibannya, yang seharusnya dia lakukan, terhadap diri sendiri, masyarakat, lingkungan, Negarara, dan Tuhan yang Maha Esa.

Sando ba'awa te Waeri Wondu ipeculaculamo ngkaumpehano kai tora mpendua sai ari kumaho Wangkinamboro. Sa'ari iko lakino lipu ipecula-culamo inalamino arino iko ndo pogaumo bendo sade mpendua.

Setelah mereka bertemu, Waeri Wondu menceritakan kejadian yang menimpanya hinggah dia bisa hidup kembali setelah dimakan oleh Wa Ngkinamboro. Lakinolipu juga menceritakan apa yang dialaminya. Mereka lalu berjanji akan bersatu lagi.

Pada kutipan di atas jelas tanggung jawab seorang suami yang ingin kembali bersatu dengan keluarganya. Melihat istrinya masih hidup, sang suami yang selama ini menduga bahwa istrinya telah mati karena dimakan oleh Wa Ngkinamboro. Dalam pertemuan singkat itu, mereka saling menceritakan kisah yang telah menimpah mereka dan membuat keluarga itu berpisah.Hinggah akhirnya Lakinoipu memutuskan untuk kembali pada istrinya, Waeri Wondu untuk membina kembali kelurga dan melaksanakan kewajibannya sebagai seorang suami sekaligus seoarang ayah yang sebelumya dipisahkan oleh Wa Ngkinamboro.

\subsection{Deskripsi Nilai Pendidikan Karakter Dalam Cerita rakyat Raja Indara Pitara}

\subsubsection{Nilai Pendidikan Karakter Kerja Keras}

Kerja keras merupakan perilaku yang menunjukan upaya yang sungguh-sungguh dalam mengatasi berbagai hambatan belajar dan tugas, serta menyelesaikan tugas sebaikbaiknya. Kerja keras juga dapat diartikan bekerja mempunyai sifat yang bersungguhsungguh untuk mencapai apa yang ingin dicapai. Seperti pada kutipan berikut:

Keu iko mohalu to'u bo pinone rouno ompole riuno, riuno ipekabali-bali lakoano mentasihano te duka ibuke'o kadadi mosega.

Pohon itu sangat susah untuk dipanjat karena memiliki banyak duri, duri yang sangat tajam dan berpindah-pindah tempat dan juga dipenuhi oleh mahluk halus.

Dari kutipan cerita di atas tampak sikap Indara Pitara yang bersikeras untuk medapatkan buah Wa Ode Kungkumabulawa. Walaupun pohon itu memiliki banyak duri dan sulit untuk dipanjat tetap saja ia berupaya untuk mendaparkan buah tersebut.

8 | Jurnal BASTRA (Bahasa dan Sastra), Vol. 5 No.1, Edisi Januari 2020/e-ISSN: 2503-3875/ http://ojs.uho.ac.id/index.php/BASTRA 


\subsubsection{Nilai Pendidikan Karakter Rasa Ingin} Tahu

Rasa ingin tahu yaitu sikap dan tindakan yang selalu berupaya untuk mengetahui lebih mendalam dan meluas dari sesuatu yang dipelajarinya, dilihat, dan didengar. Seperti pada cerita rakyat Raja Indara Pitara:

Sameantano saluwuo miano kampo ndo tehingkamo inaio pesepa boto.Saluwuinda mia ndo banga inaio anantama pesepa satekano hinamo ida'a.Raja ipontenamo bendo hohalu'o pesepa iko.

Keesokan harinya warga dibuat geger dengan aksi penyepak raga.Semua orang kagum sekaligus penasaran oleh sosok penyepak raga yang telah menghilang begitu saja bagai ditelan bumi.Raja memerintahkan untuk mencari penyelidikan.

Pada kutipan cerita menggambarkan rasa penasaran warga sekaligus sang raja terhadap Indara pitara yang menghilang begitu saja. Sang raja ingin mengetahui siapa yang telah menyepak raga sampai masuk di jendela sang putri. Sang raja pun memerintahkan para pengawal kerajaan untuk mencari pemuda tersebut. Karena rasa ingin tahu raja mereka pun menyelidiki siapakah pemuda yang berhasil menyepak raga. Sikap sang raja yang ingin mengetahui tentang pemuda tersebut dapat dicontoh. Dengan adanya hal ini, peserta didik juga harus memiliki sikap rasa ingin tahu yang tinggi tentang apa yang dipelajarinya.

\subsubsection{Nilai Pendidikan Karakter Bersahabat/Komunikatif Nilai pendidikan karakter} bersahabat/komunikatif yaitu tindakan yang memperlihatkan rasa senang berbicara, bergaul, dan bekerja sama dengan orang lain. Komunikasi memiliki peranan penting baik itu secara personal maupun antar masyarakat agar terjadi keserasian dan menghindari konflik dalam lingkungan masyarakat.

Malingu pekato'orino ndo boboiho bei polaha mesepano. Tampu'uno nai ehe. Ako sai mencundu ndo kora bumoboiho mia ompole Indara pitara i ehemo mesepa.
Beberapa orang kenalannya membujuknya untuk ikut pertandingan sepak raga. Awalnya ia menolak. Namun, setelah beberapa hari dibujuk oleh orang banyak Indara Pitara mau mengambil raga.

Kutipan cerita di atas mencerminkan nilai pendidikan karakter bersahabat/komunikatif pada sikap memperlihatkan rasa senang warga terhadap Indara Pitara yang mengajaknya untuk mengikuti sebuah pertandingan. Awalnya Indara Piatara memang tak mau dengan ajakan teman-temannya akan tetapi setelah beberapa hari dibujuk ia pun mau mengikuti pertandingan.

\subsubsection{Nilai Pendidikan Karakter Peduli Sosial \\ Nilai pendidikan karakter peduli} sosial merupakan sikap dan tindakan yang selalu ingin memberi bantuan pada orang lain dan masyarakat yang membutuhkan. Kepedulian sosial dalam kehidupan bermasyarakat lebih kental diartikan sebagai perilaku baik seseorang terhadap orang lain di sekitarnya, sebagai manusia berkarakter, kepedulian kita antar sesama sangat diperlukan. Seperti pada ceritaRaja Indara Pitara, kepedulian si nenek untuk merawat seorang anak yang diterbangkan oleh raja petir.

Inade icunanio isade raha dumano ilempeno larongkeu irahano apuancina ndo kora ngume hakono Bangke-bangkele. Apuancina kamolihini aiso rouno ipo'awa samia ana bo walino mesaka'i te inade. indara piatara iowose membalii samia ananatama mahampa. Inade imokua mokowalio kumaraja akono wa'apua.Wa'apuapo ipiara'o moiko kana apua wutono.

Ia dijatuhkan di sebuah rumah yang berada dipinggir hutan milik seorang nenek yang biasa disebut Bhangke-Bhangkele. Si nenek merasa sangat gembira karena mendapatkan seorang anak yang bisa jadi penghibur dalam hidupnya.Raja indara pitara tumbuh menjadi seorang pemuda yang gagah.Ia sangat rajin membantu pekerjaan si nenenk. Si nenenk pun memperlakukannya sebagaimana cucunya sendiri. 
Dari kutipan di atas dikategorikan sebagai nilai pendidikan karakter peduli sosial karena kepedulian dan perasaan yang menunjukkan sebuah hubungan dimana kita mempersoalkan kehadiran orang lain. Si nenek yang merespon positif atas kehadiran anak yang diterbangkan oleh raja petir, walaupun bukan cucunya sendiri tetapi si nenenk merasa sangat bahagaia dan memperlakukannya seperti cucunya sendiri dan merawatnya hingga anak itu tumbuh menjadi pemuda yang gagah.

\subsubsection{Nilai pendidikan Karakter}

\section{Tanggung Jawab}

Tanggung jawab merupakan sikap dan perilaku seseorang untuk melaksanakan tugas dan kewajibannya, yang seharusnya dia lakukan, terhadap diri sendiri, masyarakat, lingkungan, Negarara, dan Tuhan yang Maha Esa. Tanggung jawab itu bersifat kodrati, artinya sudah menjadi bagian kehidupan manusia, bahwa setiap manusia pasti dibebani dengan tanggung jawab.

Sabucuno, isade po'iaha daho samia raja imoiko te duka ipomasiako. Raeyatino ndo moiko te duka hinai da'a dumidia inda. Ako kamolihino raja irasaio hinapoi kahu rouno hinapoi duma anano.

Pada zaman dahulu, di sebuah kerajaan bertahtahlah seoarang raja yang arif dan bijaksana.Rakyatnya pun hidup aman dan sejahterah. Sayangnya kebahagiaan sang raja serasa belum lengkap karena belum juga dikaruniai seorang anak.

Pada kutipan cerita di atas di kategorikan sebagai nilai pendidikan karakter tanggung jawab karena dalam kutipan cerita menggambarkan sikap raja yang bertanggung jawabuntuk melaksanakan tugasnya dengan baik, tidak hanya di istana ia sebagai raja di negeri itu juga melakukan tanggung jawabnya terhadap rakyatnya untuk membuat rakyatnya hidup aman dan sejahtera. Walaupun keluarga sang raja sedang terbelit masalah, ia tetap melaksanakan tugas dan kewajibannya sebagai seorang raja.

\subsection{Relevansi Penelitian dengan \\ Pembelajaran di Sekolah \\ Dengan adanya penelitian tentang} cerita rakyat Kulisusu, yang di dalamnya memuat nilai pendidikan karakter ini dapat digunakan di sekolah untuk dijadikan patokan atau contoh sebagai bahan pembelajran sastra sehinggah melalui cerita rakyat Kulisusukarakter positif siswa dapat dibentuk sesuai dengan tujuan pendidikan nasionak. Berdasrkan silabus pembelajaran bahasa Indonesia, hasil penelitian tentang cerita rakyat berdasrkan Kurikulum tiga belas (K13) terdapat pada kelas $\mathrm{X}$ semester II, yaitu dengan kompetensi dasar mengidenti fikasi nilai-nilai dan isi yang terkandung dalam cerita rakyat (hikayat) yang didengar dan dibaca. Melalui pembelajaran cerita rakyat siswa dapat mendata pokok-pokok isi, dan nilai-nilai dalam hiakayat, dan mempresentasikan, menanggapi, dan merevisi teks eksposisi yang telah disusun.

\section{PENUTUP}

Kesimpulan

Cerita rakyat Zaenab te Hamid, Randasitagi te Puteri Waeri Wondu, dan Raja Indara Pitara" dalam kedudukannya sebagai sastra daerah mengandung nilai-niali pendidikan karakter yang sangat bermanfaat bagi masyarakat dan pada peserta didik.

Adapun nilai-nilai pendidikan karakter dalam cerita rakyat tersebut adalah sebagai berikut:

1. Nilai pendidikan karakter religius,

2. Nilai pendidikan karakter kerja keras,

3. Nilai pendidikan karakter mandiri,

4. Nilai pendidikan karakter rasa ingin tahu

5. Nilai pendidikan karakter brsahabat/komunikatif,

6. Nilai pendidikan karakter gemar membaca,

7. Nilai pendidikan karakter peduli sosial,

8. Nilai pendidikan karakter tanggung jawab.

Saran

Berdasarkan kesimpulan tersebut, penulis memberikan saran kepada pembaca demi terciptanya karya baru, adapun saran tersebut sebagai berikut:

1. Bagi guru, diharapkan mampu mengembangkan bahan pembelajaran yang berkaitan dengan kompetensi dasar yang telah ditentukan.

2. Bagi siswa, melalui penelitian ini diharapkan mampu menambah 
wawasan untuk merangsang kepekaan siswa terhadap majas yang terdapat dalam karya sastra khususnya cerita rakyat.

Perlu penelitian lanjutan dan pengkajian yang lebih mendalam lagi yang berkaitan dengan penelitian nilai-nilai pendidikan kakrakter dalam cerita rakyat Kulisusu "Zaenab te Hamid, Randasitagi te Waeri Wondu, dan Raja Indara Pitara" di Kabupaten Buton Utara, agar tidak hilang dan terancam punah serta masih ada dan hidup pada generasi berikutnya.

\section{DAFTAR PUSTAKA}

Amir, Ardiyetti.2013. Sastra Lisan Indonesia.Yogyakarta: $\quad \mathrm{CV}$ ANDI OFSET.

Danandjaja, James. 1997. Folkor Indonesia (Ilmu Gosip, Dongeng, dan Lain-lain). Jakarta: PT Pustaka Utama Grafiti.

Djajasudarma, Fatimah, dkk.1997. Nilai-nilai dalam Ungkapan dan Peribahasa Sunda. Jakarta: Pusat Pembinaan dan pengembangan Bahasa.

Endraswara, Suwardi. 2013. Metodologi Penelitian Sastra.Yogyakarta: Caps.

Faruk. 2014. Pengantar Sosiologi Sastra, dari Strukturulisme Genetik sampai PostModernisasi. Yogyakarta: Pustaka pelajar.

Fatabun, dkk.2000. Struktur Sastra Lisan Sentani, Prosa. Jakart: Pusan pembinaan dan Pengembangan Bahasa.

Gusal, La Ode. 2015. Nilai-nilai Pendidikan dalam Cerita Rakyat Sulawesi Tenggara Karya La Ode Sidu. Jurnal Humanika No. 5, Vol. 3/ISSN 1979-8296..

Rahmawati, dkk.2010. Inventarisasi Sastra Daerah Sulawesi Tenggara.Kendari: Kantor Bahasa Profinsi Sulawesi Tenggara.

Rahmawati. 2014. Ungkapan Tradisional Muna. Kendari: Kantor Bahasa Profinsi Sulawesi Tenggara.

Samani, Muchlas, dkk. 2017. Konsep dan Model Pendidikan Karakter. Bandung: PT Remaja Rosdakarya Offset.

Tomaso, dkk. 2000. Sejarah dan Perkembangan Sastra Indonesia di Maluku. Jakarta: Pusat Bahasa.
Udin, Nazaruddin, 1998. Sastra Lisan Lampung. Jakarta: Pusat Pembinaan dan Peng

embangan Bahasa.

Wibowo, Agus. 2013. Pendidikan Karakter Berbasis Sastra. Yogyakarta: Pustaka Pelajar.

Wicaksono, Andri. 2014. Pengkajian Prosa Fiksi. Yogyakarta: Penerbit Garudhawaca.

Yuwono, Untung. 2007. Gebang Sastra Indonesia Klasik.Jakarta: Wedatama Widya Sastra. 